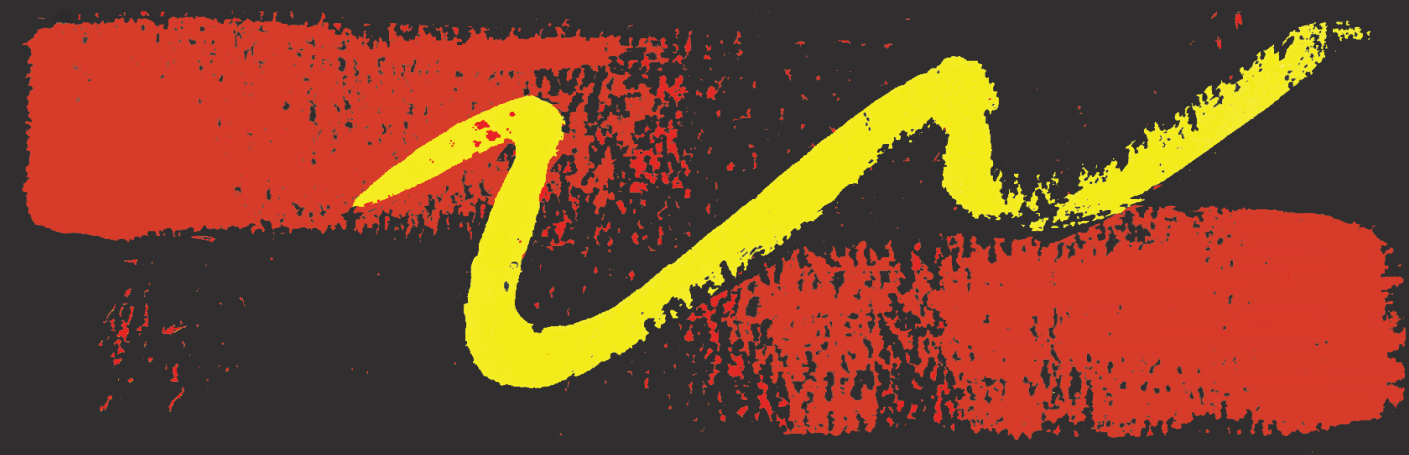

Vol. XXV (2), 2007

ISSN 0254-9247
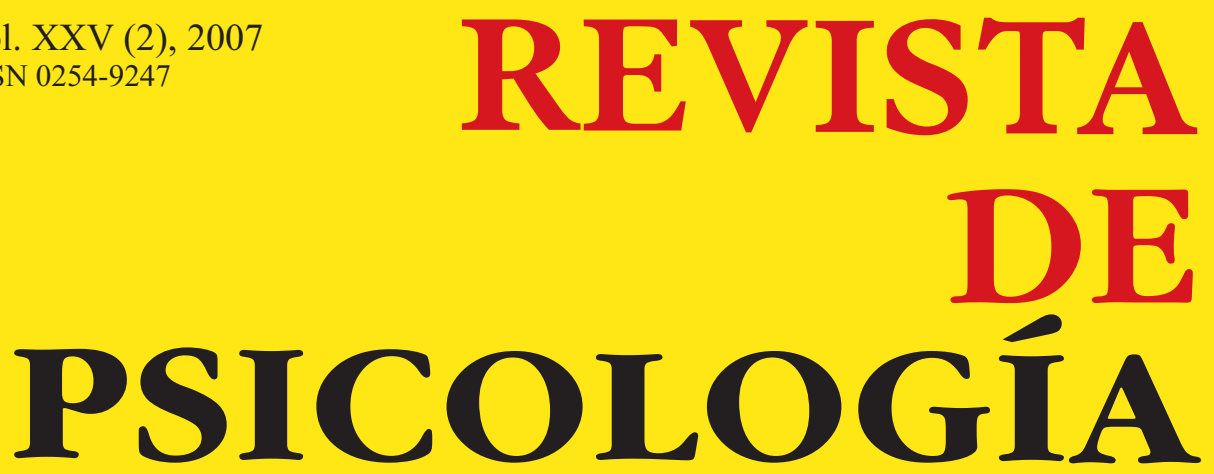

Ana María Anguas-Wong

María Ángeles Bilbao

Gloria Burga

Alicia Calderón-Prada

Agustín Espinosa

Ana Rosa Feijoo

Jessica Güímac

Rom Harré

Naomi Lee

David Matsumoto

Fathali M. Moghaddam

Darío Páez

Peter B. Smith

Elza María Techio

Jorge Yamamoto 


\section{REVISTA DE PSICOLOGÍA}

ISSN 0254-9247

Vol. XXV (2), 2007

\section{CONTENIDO}

INTRODUCCIÓN

\section{ARTÍCULOS}

Fathali M. Moghaddam, Naomi Lee y Rom Harré. Psychology is social: Exploring universals in performance capacity and performance style

Peter B. Smith. Towards studies of organizational behaviour with greater local relevance

Jorge Yamamoto y Ana Rosa Feijoo. Componentes émicos del bienestar. Hacia un modelo alternativo de desarrollo

María Ángeles Bilbao, Elza María Techio y Darío Páez. Felicidad, cultura y valores personales: estado de la cuestión y síntesis meta-analítica

Ana Maria Anguas-Wongy David Matsumoto. Reconocimiento de la expresión facial de la emoción en mexicanos universitarios 
Agustín Espinosa, Alicia Calderón-Prada, Gloria Burga y Jessica Güimac. Estereotipos, prejuicios y exclusión social en un país multiétnico: el caso peruano 
Revista de Psicología Vol. XXV (2), 2007 (ISSN 0254-9247)

\title{
Felicidad, cultura y valores personales: estado de la cuestión y síntesis meta-analítica
}

\author{
María Ángeles Bilbao, ${ }^{1}$ Elza María Techio ${ }^{2}$ y Darío Páez ${ }^{3}$ \\ Universidad del País Vasco, España
}

\begin{abstract}
Este estudio presenta un meta-análisis sobre la relación entre los valores de Schwartz y el bienestar subjetivo en distintos contextos culturales, con estudiantes, sus familiares e inmigrantes en España. Los resultados confirman una asociación significativa entre los valores y el bienestar. Auto trascendencia y apertura al cambio, y con menor intensidad, conservación, se asocian positivamente con mayor bienestar. Auto trascendencia se asocia con felicidad y satisfacción de forma positiva no homogénea, siendo los inmigrantes quienes presentan medias más bajas. Apertura al cambio se asocia con felicidad, siendo más fuerte la asociación en inmigrantes que en estudiantes. Los valores conservacionistas se asocian homogéneamente. Un segundo estudio sobre criterios de salud psicosocial y bienestar subjetivo -analizando un país sudamericano colectivista y jerárquico como Brasil, y otro europeo más individualista e igualitario como España- confirma que los valores conservacionistas, así como los de apertura al cambio y auto trascendencia, son deseables y favorecen el bienestar.

Palabras clave: meta-análisis, valores, bienestar subjetivo, estudio transcultural.
\end{abstract}

Happiness, culture and personal values: State of the art and meta-analytical synthesis

This article presents a meta-analysis of the relationship between Schwartz personal values and subjective well-being among different cultural contexts, with students, their families, and immigrants in Spain. Results show a significant association between personal values and well-being. Self-transcendence and openness to change, as well as conservation, but with less intensity, are positively associated with greater well-being. Self-transcendence is non-homogenous and positively associated with both happiness and satisfaction, being the immigrants who present lower levels. Openness to change is associated with happiness, being this relationship stronger for immigrants than for students. Conservation values are homogenously associated with subjective well-being. A second study about psychosocial health and subjective well-being analyzes two countries: a collectivist and hierarchical South American country as Brazil, and another one more individualistic and egalitarian as Spain. Results corroborate that conservation values, as well as openness to change and self-transcendence, are desirable and beneficial for subjective well-being.

Keywords: Meta-analysis, values, subjective well-being, cross-cultural study. 



\section{Cultura, bienestar subjetivo y valores básicos individuales}

Los estudios en el ámbito del bienestar subjetivo han mostrado que los atributos de felicidad, satisfacción con la vida o bienestar psicológico y social, se asocian entre sí y varían en diferentes contextos culturales. El término bienestar subjetivo ha sido utilizado ampliamente como equivalente al de satisfacción con la vida y al de felicidad, ya que los tres hacen referencia a un sentimiento emocional básico sobre la evaluación global de la calidad de la vida personal, es decir, cuánto le gusta a una persona la vida que lleva (Veenhoven, 1994). Además, es más permanente que el estado de humor o ánimo, pudiendo distinguirse en términos genéricos dos componentes del bienestar subjetivo, los aspectos cognitivos del bienestar, representados por la apreciación de satisfacción con la vida, y los aspectos afectivos o emocionales, representados por la balanza de afectos o percepción personal de la felicidad I tristeza (Argyle \& Martin, 1991).

1 Licenciada en Psicología por la Universidad de Chile. Candidata a Doctor en Psicología por la Universidad del País Vasco, España. Áreas de investigación: bienestar subjetivo, promoción de la salud, temáticas sobre bienestar en infancia y juventud. Dirección postal: Universidad del País Vasco, Facultad de Psicología, Departamento de Psicología Social y Metodología de las Ciencias del Comportamiento, Av. Tolosa 70, 20018, San Sebastián, España. Correo electrónico: mbilbaor@uc.cl

2 Licenciada en Psicología por la Universidad Federal da Paraíba, Brasil. Realizó sus estudios de postgrado en Psicología Social Cognitiva en la misma institución. Candidata a Doctor en Psicología por la Universidad del País Vasco, España. Áreas de investigación: relaciones intergrupales, emociones, bienestar y memoria colectiva. Dirección postal: Universidad del País Vasco, Facultad de Psicología, Departamento de Psicología Social y Metodología de las Ciencias del Comportamiento, Av. Tolosa 70, 20018, San Sebastián, España. Correo electrónico: elzamt400@gmail.com

3 Catedrático de Psicología Social en la Universidad del País Vasco, España. Áreas de investigación: relaciones intergrupales, memoria colectiva, inmigración, salud mental, impacto de la violencia colectiva sobre la cultura y clima emocional. Dirección postal: Universidad del País Vasco, Facultad de Psicología, Departamento de Psicología Social y Metodología de las Ciencias del Comportamiento, Av. Tolosa 70, 20018, San Sebastián, España. Correo electrónico: dariopaez@ehu.es 
Las investigaciones sobre el bienestar subjetivo han recopilado un conjunto sustancial de conocimientos con respecto a los atributos, las características personales y las situaciones objetivas que explicarían distintos niveles de bienestar entre las personas. Mayores niveles de bienestar subjetivo suponen, a nivel colectivo: desarrollo económico (Lima $\&$ Novo, 2006), cultura individualista en la que las personas tienen una mayor libertad para elegir sobre su propia vida, preocupación por la igualdad social y legitimación de relaciones sociales igualitarias. A nivel individual suponen, entre otros: factores psicológicos que contribuyen a tener una red social activa y positiva, que disminuyen la afectividad negativa y aumentan la positiva, una autoestima positiva y estar abierto a nuevas experiencias, además de apoyo social, estrategias adecuadas de afrontamiento y buena salud física y mental (Barrientos, 2005). Dentro de las distintas líneas de investigación, una que aporta una comprensión transversal de los anteriores se encuentra en el aporte al bienestar subjetivo de los valores básicos individuales.

Los valores básicos individuales están presentes en la mayoría de las conductas motivadas de las personas. Los valores han sido definidos como creencias conectadas a emociones (no creencias objetivas), culturalmente construidos como objetivos o metas abstractas que dirigen a las personas, que trascienden a situaciones y acciones particulares estableciendo estándares que ordenan nuestra conducta con los demás y la evaluación del mundo que nos rodea (Páez, Fernández, Ubillos \& Zubieta, 2004). La teoría de Schwartz (1992) sobre los valores básicos universales describe diez tipos motivacionales (valores), donde cada valor refleja metas y objetivos que las personas buscan conseguir y marcarían las acciones que emprenden para conseguirlos. Estos tipos motivacionales serían bastante estables y comunes en todas las culturas, variando respecto de su intensidad o importancia y su asociación con aspectos culturales particulares. Los valores propuestos por Schwartz han sido ampliamente estudiados, confirmándose la estructura propuesta en más de 60 países. Los valores o tipos motivacionales se agruparían en: universalismo, benevolencia, tradición, conformidad, seguridad, po- 
der, logro, hedonismo, estimulación y auto dirección. Éstos se organizan como un sistema íntegro de prioridades que guían la vida de las personas, estableciéndose una relación dinámica entre ellos (Schwartz, 1992).

De estos diez valores emergerían dos dimensiones bipolares ortogonales que configuran objetivos generales de apertura al cambio o a la experiencia (estimulación y auto dirección) opuesto a conservación (tradición, conformidad y seguridad), y auto promoción o promoción personal (poder, logro y hedonismo) opuesto a auto trascendencia (universalismo y benevolencia) (Páez et al., 2004; Schwartz, 1992). Finalmente, Schwartz plantea que algunos valores pueden estar asociados a nivel colectivo en términos de intereses individualistas (logro, poder, auto dirección, estimulación y hedonismo) o colectivistas (conformidad, tradición y benevolencia). Las características a nivel colectivo de los colectivistas estarían centradas en valores de lealtad y dependencia de los grupos a los que se pertenece, asociándose a objetivos generales de conservación. Los individualistas, a nivel colectivo, se caracterizarían por priorizar objetivos generales de promoción personal y apertura al cambio (Páez et al., 2004).

Con respecto a los efectos de los valores en el bienestar se han planteado dos hipótesis, la del efecto directo y la de la congruencia. La primera hipótesis plantea que habría valores que serían intrínsecamente positivos para el bienestar, ya que se asocian a una balanza de afectos positivos y a criterios de salud mental psicosocial, como la auto dirección y la benevolencia, asociados a la autonomía personal y a una buena integración social respectivamente. Habría también valores asociados negativamente, como los de poder, asociados a metas extrínsecas como la búsqueda de reputación y éxito material, o los de conformidad, que limitaría la autonomía personal. La hipótesis de la congruencia plantea que los valores serían beneficiosos cuando fueran coherentes con los valores dominantes, o a la inversa, que valorar mucho la auto dirección en un medio en que predomina la conformidad y tradición, provocaría 
frustración y conflicto, y por ende malestar. Los estudios transculturales han ilustrado cómo los valores básicos individuales modulan las necesidades y motivos hedónicos, de seguridad, los relacionales, de autoestima, de logro, control, afiliación e intimidad. Se ha planteado que el bienestar sujetivo, por un lado, podría depender del perfil personal de estos valores individuales, siendo quizás algunos valores en particular más importantes para un bienestar subjetivo alto. Por otro lado, el poder concretar satisfactoriamente estos valores individuales en la vida personal llevaría a un mayor bienestar subjetivo (Sagiv \& Schwartz, 2000). Es decir, el bienestar subjetivo estaría determinado en parte por la congruencia entre los valores personales y la jerarquía de valores dominante en el entorno social. La hipótesis de congruencia con el entorno plantea que en contextos culturales y sociales que valoren, por ejemplo, la seguridad, la tradición y el conformismo, las personas que aprueben mucho estos valores tendrán mayor bienestar, ya que compartir estos valores ayuda al ajuste social. Esto es lo que sugieren Sagiv y Schwartz (2000) cuando plantean que en contextos individualistas y competitivos -como sería el de estudiantes de economía y negocio-, el bienestar estaría reforzado en las personas que valoran principalmente el poder y el logro. Si bien sus resultados confirman esta hipótesis, otros estudios han encontrado que las personas centradas en valores materialistas o extrínsecos presentan menor bienestar subjetivo, así como menor felicidad general y mayor ansiedad, uso de sustancias y malestar físico, aun en congruencia con los valores del contexto (Kasser \& Ahuvia, 2002; Vansteenkiste, Duriez, Simons \& Soenens, 2006).

Esta hipótesis, aunque existe variación interna a nivel individual en los países, también se puede interpretar en un sentido de variabilidad cultural: valores universalistas y benevolentes, las relaciones sociales con otros y el bienestar social serían importantes y se asociarían al bienestar en culturas igualitarias, mientras que valores de poder y logro, rendimiento, autoestima y control del yo se asociarían al bienestar en culturas jerárquicas y competitivas; valores de auto dirección, control y autonomía del yo y afectividad positiva se asociarían de forma más 
importante al bienestar en culturas individualistas; finalmente, valores de conformidad y tradición, integración social y sentido de la vida se asociarían más fuertemente a culturas colectivistas (Basabe \& Ros, 2005; Green, Deschamps \& Páez, 2005). Los estudios realizados por el European Social Survey (Vala \& Torres, 2006) en 20 países europeos encontraron una asociación positiva, aunque leve, entre los valores y el bienestar subjetivo (Lima \& Novo, 2006). Por otro lado, el nivel de escolaridad, coincidente con el nivel de desarrollo económico, correlacionó positiva y significativamente con los valores de auto trascendencia, propios de las culturas post-materialistas europeas, es decir, mayores índices de escolaridad implican individuos más igualitarios, reflexivos, humanistas y tolerantes que se orientarán a objetivos contextuales más que a seguir valores institucionalizados culturalmente (Ramos, 2006). Esto genera también una mayor variabilidad al interior de los países respecto de la jerarquía de valores, lo que implicaría que cuanto mayor es el desarrollo económico menos aplicable al conjunto de la sociedad es la hipótesis de congruencia cultural.

Finalmente, también se puede razonar que dado que los valores designan lo que es deseable, valorar mucho la autonomía o la seguridad puede ser un mecanismo compensatorio de una realidad constrictora o alienante, o de una realidad insegura. En este sentido, se puede decir que valorar mucho la auto dirección se daría en contextos que limitan respectivamente la autonomía y variedad de la experiencia, así como valorar la auto trascendencia, compuesta de universalismo y benevolencia, se daría en los que hay poca justicia para todos y en los que la gente no se preocupa por el bienestar de los otros.

\section{Colectivismo, valores de seguridad, tradición y conformidad y bienestar}

Se ha encontrado que contextos culturales colectivistas, jerárquicos, competitivos o masculinos y de alta evitación de la incertidumbre, 
muestran menor felicidad, menor satisfacción y una peor balanza de afectos (Basabe et al., 2002). Probablemente, una mayor represión emocional unida a un entorno más estresante explicaría la menor felicidad de las culturas jerárquicas y colectivistas. Las culturas individualistas, por el contrario, aceptarían más la expresión de emociones positivas, lo que explicaría en parte su mayor bienestar. Cabe señalar que la frecuencia de episodios emocionales positivos no diferencia a contextos individualistas de colectivistas, sin embargo, las culturas jerárquicas muestran mayor frecuencia de emociones negativas y menor deseabilidad de las emociones (Basabe et al., 2000). La influencia negativa del colectivismo se mantiene cuando se controla el nivel de desarrollo económico, sugiriendo que los valores dominantes en parte explicarían esta menor felicidad. Los valores de seguridad, tradición y conformidad se reúnen en un síndrome conservacionista y son más dominantes en naciones colectivistas (Basabe \& Ros, 2005; Páez \& Zubieta, 2004). Los estudios del meta-análisis realizado por Basabe et al. (2002) mostraron que la media nacional de valores colectivistas se asocia negativamente a la media nacional de felicidad. Además de esta evidencia colectiva, hay resultados individuales similares: los valores personales de seguridad, tradición y conformidad se asociaban negativamente con la felicidad de los sujetos en el estudio de Sagiv y Schwartz (2000), medida por la afectividad positiva de la escala de Bradburn, respectivamente: $r=-.13$, $r=-.08$ y $r=-.12$ ( $p<.01$, para todas las correlaciones).

Los valores de conservacionismo o colectivistas, sin embargo, por su énfasis en la tradición y el respeto de las normas, pueden ayudar a tener un propósito en la vida y a la integración social. El estudio de Lima y Novo (2006) encontró con muestras representativas de 20 países de la Unión Europea una asociación positiva entre valores colectivistas o conservacionistas y un indicador de bienestar subjetivo. La fuerza de la asociación era similar en países de diferente desarrollo socioeconómico (total 20 países, $r=.26, p<.001$ ), sugiriendo que estos valores tienen un efecto positivo en diferentes contextos culturales, aunque es verdad que limitado al ámbito europeo (Lima \& Novo, 2006). 
El valor de seguridad implica valorar como objetivos la estabilidad, seguridad y supervivencia de la persona, sus relaciones y familia. Los valores de seguridad se enfatizarían más en contextos menos desarrollados, colectivistas y jerárquicos o materialistas -en los términos de Inglehart-, ya que en estas culturas el desarrollo social es menor, la sociedad menos previsible y con mayores niveles de problemas, por lo que la obtención de recursos para asegurar la vida social y un entorno seguro son objetivos importantes (Inglehart, Basañez, Diéz-Medrano, Halman \& Luijkx, 2003).

Los valores de tradición enfatizan como metas relevantes el respeto, el compromiso y la aceptación de las costumbres e ideas, incluyendo la religión. Los valores de conformidad enfatizan la obediencia, la buena educación, el auto control y la conformidad con las normas. Culturas colectivistas enfatizarían la obediencia a las normas endogrupales, así como el respeto al pasado, a los mayores y a las costumbres, por lo que en éstas predominan más estos valores. Aunque este conjunto de valores inhibe la autonomía, la libertad y el control, por otro lado ayuda a satisfacer las necesidades de sentido, control y orden del mundo.

\section{Cultura individualista, valores de necesidad hedónica y bienestar}

Las culturas individualistas, además de tener un nivel de desarrollo social mayor, comparten valores más fuertes de estimulación y placer, asociados a poner énfasis en la satisfacción de necesidades hedónicas. Esto puede explicar en parte la mayor felicidad en estas sociedades -el individualismo se asocia a mayor felicidad, aún controlando el nivel de desarrollo socio-económico (Basabe et al., 2002). Además, en estas culturas valoran más los atributos personales y la independencia o autonomía de la persona, por lo que es comprensible que los atributos internos y la autonomía sean más importantes para el bienestar. Esta idea se ve avalada por el hecho de que la relación entre frecuencia de emociones negativas y positivas, la balanza de afectos, se asociaba más 
fuertemente con la satisfacción vital en las culturas individualistas que colectivistas (Suh, 2000).

Los valores de auto dirección, hedonismo y estimulación, son más importantes en naciones con cultura individualista (Basabe \& Ros, 2005). El valor de estimulación enfatiza como metas y fines la novedad, una vida excitante y el desafío, se asocia a la satisfacción de la necesidad hedónica y, en parte, de crecimiento. El valor de hedonismo enfatiza como fines los placeres y gozos de la vida, estando asociado a la necesidad hedónica. El valor de auto dirección enfatiza la independencia de acción y pensamiento, la libertad y elección de sus propias metas, asociándose a la necesidad de control, autonomía y competencia (Sagiv \& Schwartz, 2000). Estos valores se asociarían a motivos hedónicos, de control, competencia y autonomía, así como en parte a la necesidad de crecimiento. Dado su énfasis en metas positivas, estos valores se asociarían más fuertemente al bienestar.

Valores de auto dirección se asocian al criterio de salud mental de autonomía y motivación intrínseca, reforzando el control, la auto eficacia y la autoestima; el hedonismo, a la exposición a situaciones y estímulos positivos, reforzando la afectividad positiva. La estimulación se asocia a variedad de experiencia, desafío y probablemente a los criterios de salud mental de crecimiento personal. Auto dirección, estimulación y hedonismo se asocian en general a la felicidad, confirmando que los valores individualistas, que enfatizan valores de crecimiento y desarrollo personal, como la autonomía y el hedonismo, son congruentes con un estado afectivo adaptativo (Sagiv \& Schwartz, 2000).

\section{Culturas de alta distancia al poder, valores de logro y poder, competencia y control, $y$ felicidad}

Los valores de promoción personal se asocian a contextos culturales jerárquicos. Dado que en estas naciones el nivel de felicidad es menor, 
aun controlando el desarrollo social, podemos suponer que los valores dominantes juegan un papel en la menor felicidad (Basabe et al., 2002). El valor de poder que enfatiza metas de estatus, prestigio y dominio de la gente, se asocia a la necesidad de control y de autoestima, aunque vinculada a recompensas extrínsecas materialistas y de aprobación social (Vansteenkiste et al., 2006). Sagiv y Schwartz (2000) encontraron que el valor de poder se asociaba negativamente pero de forma no significativa a medidas de felicidad. Los resultados obtenidos por Vansteenkiste et al. (2006), si bien utilizando el Índice de Aspiraciones de Kasser y Ryan, muestran asociaciones negativas entre las variables de valores extrínsecos (éxito económico, apariencia física y fama) con bienestar $(r=-.22, p<.001)$ y positivas con abuso de sustancias y estrés interno $(r=.36, p<.001 ; r=.13, p<.05$, respectivamente). Además, el valor de poder se asoció a una visión negativa del yo y del mundo, $r=.09$ con apego temeroso y $r=-.09$ con seguro, $p<.10$ (Páez et al, 2004).

El valor de logro enfatiza las metas de éxito personal demostrando un rendimiento acorde con las normas y se asocia a la necesidad de competencia. Puede asociarse al rendimiento, a la auto eficacia y, por ende, a los criterios de propósito en la vida y de control del medio. El valor de poder se asocia a valorar la reputación y los bienes materiales, por lo que se asociaría negativamente al bienestar, ya que valores materialistas y motivación extrínseca se asocian al malestar (Kasser \& Ahuvia, 2002). En la medida en que el rendimiento se asocie a la motivación intrínseca, al rendimiento en base a normas internalizadas, se asociaría a mayor bienestar, según el estudio de Sagiv y Schwartz (2000), en el cual logro correlacionó con felicidad $(r=.10, p<.01)$. Podemos concluir que el valor de logro se asocia a la felicidad en algunos contextos, probablemente de asimetría social y necesidad de rendir para ascender. La evidencia sobre los efectos negativos del valor de poder es limitada, aunque se asocia a una visión negativa del mundo y a peores relaciones con otros, según estudios de nuestro grupo (Páez et al., 2006). 


\section{Cultura, necesidad relacional y valores de benevolencia y universalismo}

La necesidad relacional o de gregarismo está presente en todas las culturas como una valoración a la interacción social frecuente y estable. En las colectivistas se trata de una sociabilidad de deber, estable y asociada a pocos grupos concretos a los que se adscribe el sujeto (e. g. familia extensa). Es razonable suponer que el motivo relacional de pertenencia sea más importante en estos contextos por la importancia que juegan las redes en el logro de metas personales y grupales. En las culturas individualistas se trata de una sociabilidad voluntaria, basada en la satisfacción recíproca, orientada a grupos de pertenencia variados y de adscripción relativamente voluntaria. La motivación de afiliación e intimidad es más importante en culturas individualistas, en las que las relaciones sociales son más voluntarias y se debe hacer un esfuerzo de creación y mantenimiento de ellas, en comparación con las colectivistas (Hofstede, 2001; Páez et al., 2004).

En las culturas colectivistas, que valoran la tradición y conformidad, incluso las relaciones de intimidad se asocian más a decisiones familiares, se basan en el amor compañero o estable a largo plazo y a consideraciones pragmáticas. En las culturas individualistas, que valoran la auto dirección y el hedonismo, las relaciones íntimas se basan más en el amor pasional, la atracción y los sentimientos (Hofstede, 2001; Páez et al., 2004).

El valor más vinculado a las relaciones positivas con otros es el de benevolencia, que enfatiza el bienestar de las personas cercanas. Los valores de universalismo se asocian a la aplicación de normas de justicia universal y al bienestar global, generalizado a la humanidad. Estos dos valores se asocian entre sí y generalmente se asocian a culturas igualitarias o de baja jerarquía. A nivel individual, se asocian generalmente con creencias igualitarias, correlacionando negativamente con creencias sobre la importancia de que unos grupos sociales dominen a otros (Sida- 
nius \& Pratto, 1999). Probablemente por la visión positiva del mundo social y de las relaciones, estos valores se asocian al bienestar. Además, estarían relacionados con un mayor desarrollo económico y educacional, como lo muestra el estudio de países europeos (Ramos, 2006).

En este artículo se realiza un meta-análisis de la evidencia de varios estudios realizados por nuestro grupo de investigación ${ }^{1}$ con autóctonos españoles y estudiantes de América Latina y España, así como con inmigrantes en España de América Latina, Europa del Este y África. En ellos se utilizó la Escala de Valores de Schwartz (PVQ) y se correlacionó con indicadores de bienestar tales como la Balanza de Afectos PNA de Bradburn (Warr, Barter \& Brownbridge, 1983), la Escala de Felicidad de Oxford (Argyle, 1987) y la de Satisfacción con la Vida de Diener (Lucas, Diener \& Suh, 1996).

Con el fin de entender cuáles son los aspectos de la salud psicosocial que cada conjunto de valores refuerza, se presenta un segundo estudio, en el cual se analizó la relación entre los dominios de objetivos generales y valores de Schwartz con las facetas de bienestar psicológico y del bienestar social, para dos países con distinto índice de desarrollo humano: Brasil y España.

\section{ESTUDIO UNO \\ META-ANÁLISIS SOBRE VALORES DE SCHWARTZ}

El presente meta-análisis busca responder a cuatro preguntas:

1. ¿Cuál es el tamaño del efecto estimado y éste es significativo para la relación entre los valores y la satisfacción con la vida y con el bienestar emocional?

1 Grupo Consolidado de Investigación en Psicología Social, http://www.ehu.es/pswparod/ index.asp 
2. ¿Son los resultados de estos distintos estudios homogéneos- es decir, pueden estos estudios ser considerados muestras elegidas al azar desde la misma población, o son los estudios provenientes de distintas poblaciones con diferentes tamaños del efecto para la relación investigada?

3. Si los estudios no son homogéneos, ¿qué características de las muestras y de los métodos utilizados en los estudios están relacionadas con esta variación del tamaño del efecto estimada en los diferentes estudios?

4. ¿Cuántos estudios sin la hipótesis nula rechazada serían necesarios para rebajar la asociación encontrada al combinar los estudios hasta un nivel de no-significación?

\section{Metodología}

\section{Participantes}

Las muestras utilizadas provienen de una serie de estudios transversales realizados durante los últimos cinco años por el Grupo Consolidado de Investigación en Psicología Social de la Facultad de Psicología de la Universidad del País Vasco. Los datos utilizados para el análisis, si bien han sido publicados en otros artículos, no han sido trabajados respecto de la relación entre valores y bienestar subjetivo, ni publicados en otros artículos, lo que hace del presente estudio un aporte importante para el avance del área.

De manera más específica, los estudios utilizados para elaborar el siguiente meta-análisis han contado con la participación de un total de 3665 personas. De éstas, un $64.72 \%$ son estudiantes universitarios, un $6.14 \%$ son familiares de estudiantes universitarios y un $29.14 \%$ son población inmigrante en España (para una descripción más precisa de los participantes ver la Tabla 2). 


\section{Instrumentos}

Los instrumentos utilizados por cada estudio del presente meta-análisis se encuentran descritos en la Tabla 1. A continuación se describe brevemente cada uno de ellos con las variaciones encontradas en el presente trabajo.

1. Escala de Perfiles Individuales de Valores (Portrait Values Questionnaire / PVQ) (Schwartz, 1992): busca medir los 10 tipos motivacionales descritos en la teoría de Schwartz, donde cada tipo refleja metas y objetivos que las personas buscan conseguir. Las escalas pueden variar entre 40 o 21 ítems, de los cuales se obtienen a través de la suma de ellos los siguientes valores: universalismo, benevolencia, tradición, conformidad, seguridad, poder, logro, hedonismo, estimulación y auto dirección. La puntuación es de tipo Likert y va de 1 (se parece mucho a mî) a 6 (no se parece en nada a mi), en todos los estudios analizados. Además de obtener los valores individuales ya descritos, se obtienen cuatro dimensiones u objetivos generales: apertura al cambio (estimulación y auto dirección) opuesto a conservación (tradición, conformidad y seguridad), y promoción personal (poder, logro y hedonismo) opuesto a auto trascendencia (universalismo y benevolencia) (Páez et al., 2004). Finalmente, Schwartz plantea que algunos valores pueden estar asociados a nivel colectivo en términos de intereses, obteniéndose las supradimensiones de individualismo (logro, poder, auto dirección, estimulación y hedonismo) y colectivismo (conformidad, tradición y benevolencia) (Páez et al., 2004).

2. Escala de Satisfacción con la Vida (Satisfaction with Life Scale / SWLS) (Lucas, Diener \& Suh, 1996): evalúa el grado de satisfacción de la persona con ciertos aspectos de su vida, tales como: familia, finanzas, trabajo, sí mismo, salud y vida en general. La puntuación de la escala es de tipo Likert y va de 1 (muy insatisfactoria) a 10 (muy satisfactoria). Ha sido validada tanto con otros criterios de bienestar como en distintas culturas e idiomas (Diener, Lucas \& Oishi, 2005). 
3. Escala de Afectividad Positiva y Negativa (Positive and Negative Affect Scale / PNA) (Warr, Barter \& Brownbridge, 1983): mide la afectividad o estado de ánimo, es decir, el nivel de bienestar o malestar subjetivo durante un lapso de tiempo determinado. Los dos estudios que utilizan este instrumento hacen referencia al último mes de los encuestados. El cuestionario consta de 10 ítems, provinentes de la escala original de Bradburn, a los cuales se han agregado 8. El tipo de respuesta puede oscilar entre 0 (no ha sentido) y 1 (si ha sentido) (Páez et al., 2006) o entre 1 (nunca) y 4 (casi todo el tiempo) (Zlobina, Basabe \& Páez, 2004). A través de esta escala podemos obtener una medida de la balanza afectiva, para lo cual se resta el puntaje del afecto positivo y el afecto negativo, obteniendo una estimación representativa del aspecto afectivo del bienestar subjetivo o felicidad del sujeto.

4. Escala de Felicidad de Oxford (Oxford Happiness Scale / OHS) (Argyle, 1987): mide los aspectos motivacionales-conductuales (tendencia a socializar, capacidad de gozar de las gratificaciones), afectivos (buen estado de ánimo, calma), cognitivos (optimismo, visión positiva del yo y del futuro) y fisiológicos (capacidad para dormir bien, vitalidad, apetito normal), de la felicidad individual. Esta escala es una inversión de los ítems de depresión de Beck, más la suma de ítems específicos sobre felicidad. Se puede obtener una medida global de felicidad al sumar los 29 ítems, así como 6 dimensiones, las cuales no fueron utilizadas en el presente estudio. La puntuación es de tipo Likert de 1 a 4, con frases acordes a lo expuesto en el ítem correspondiente. La puntuación del OHS correlaciona $r=.32$ con la Escala de Afectividad Positiva de Bradburn, $r=.57$ con la Escala de Satisfacción con la Vida de Diener, $r=-.52$ con la Escala de Depresión BDI y $r=-.32$ con la Escala de Afectividad Negativa de Bradburn (Argyle \& Martin, 1991). 
Felicidad, cultura y valores personales / Bilbao, Techio y Páez

\section{Tabla 1}

Instrumentos utilizados en cada estudio

\begin{tabular}{|c|c|c|c|c|c|c|}
\hline Estudio & $\begin{array}{c}\text { Cuestionario } \\
\text { PVQ - } \\
\text { Schwartz }\end{array}$ & Rango & $\begin{array}{c}\text { Satisfacción con } \\
\text { la vida }\end{array}$ & Rango & Felicidad & Rango \\
\hline $\begin{array}{l}\text { Mendoza } \\
\text { et al., } \\
2005\end{array}$ & 40 ítems & $1-6$ & $\begin{array}{l}\text { ¿En qué medida } \\
\text { está Ud. satisfecho } \\
\text { con su vida en } \\
\text { general, última- } \\
\text { mente? - } 1 \text { ítem }\end{array}$ & $1-10$ & $\begin{array}{l}\text { ¿En qué medida } \\
\text { está Ud. feliz últi- } \\
\text { mamente? - } 1 \text { ítem }\end{array}$ & $1-10$ \\
\hline $\begin{array}{l}\text { Páez et } \\
\text { al., } 2006\end{array}$ & 21 ítems & $1-6$ & $\begin{array}{l}\text { SWLS Diener - } \\
7 \text { ítems }\end{array}$ & $1-10$ & $\begin{array}{l}\text { Felicidad (OHS) - } \\
29 \text { ítems }\end{array}$ & $1-4$ \\
\hline $\begin{array}{l}\text { Páez et } \\
\text { al., } 2006\end{array}$ & 40 ítems & $1-6$ & $\begin{array}{l}\text { SWLS Diener - } \\
7 \text { ítems }\end{array}$ & $1-10$ & $\begin{array}{l}\text { Balanza PNA - } \\
18 \text { ítems }\end{array}$ & $0-1$ \\
\hline $\begin{array}{l}\text { Techio, } \\
2007\end{array}$ & 21 ítems & $1-6$ & $\begin{array}{l}\text { SWLS Diener - } \\
7 \text { ítems }\end{array}$ & $1-10$ & -..-.-.-. & --- \\
\hline $\begin{array}{l}\text { Zlobina, } \\
\text { Basabe } \\
\text { \& Páez, } \\
2004\end{array}$ & 40 ítems & $1-6$ & $\begin{array}{l}\text { ¿En qué medida } \\
\text { está Ud. satisfecho } \\
\text { con su vida en } \\
\text { general, última- } \\
\text { mente? - } 1 \text { ítem }\end{array}$ & $1-10$ & $\begin{array}{l}\text { Balanza PNA - } \\
18 \text { ítems }\end{array}$ & $1-4$ \\
\hline
\end{tabular}

\section{Procedimiento}

Los estudios fueron seleccionados basándose, primero, en haber aplicado el Cuestionario de Valores de Schwartz (40 ítems y reducido de 21 ítems), pudiéndose obtener las 10 dimensiones; y segundo, en haber aplicado alguna medida de satisfacción vital (SWLS de Diener) y de felicidad (Oxford, PNA de Bradburn o preguntas de satisfacción con la vida / felicidad). Sólo el estudio de Techio (2007) no incluyó preguntas sobre felicidad (ver Tabla 1).

Los estudios fueron clasificados según los instrumentos utilizados, país de los encuestados, continente de origen de los encuestados, tipo de muestra: estudiantes o inmigrantes, y contexto del estudio (ver Tabla 2). 
El tamaño del efecto utilizado en este meta-análisis es la correlación $r$ de Pearson, como indicador de la relación existente entre los valores de Schwartz y la satisfacción con la vida y el bienestar emocional. La $r$ de Pearson es una medida de fácil cálculo en las muestras, así como de fácil interpretación. Dado que los valores de Schwartz pueden ser analizados en tres ámbitos, se registraron las $r$ de Pearson para cada dimensión.

Los datos fueron analizados según las recomendaciones descritas en Rosenthal (1991). La estimación del tamaño del efecto de los 20 estudios se obtuvo según el siguiente procedimiento: a) transformación de la $r$ de cada muestra de los estudios en una $z$ de Fisher para cada muestra, b) multiplicación de la $z$ de la muestra por el peso de la muestra, c) sumatoria de todas las $z$ ponderadas de las muestras, d) sumatoria de los pesos de las muestras, e) división de la suma de las $z$ ponderadas, por la suma de los pesos, para la obtención de una media de $z$ ponderada, f) transformación de la media de $z$ ponderada en $r$.

Las $r$ ponderadas son la estimación del tamaño del efecto total basada en el conjunto de los resultados de las muestras. La estimación del tamaño del efecto combinado se realizó ponderando cada resultado de las muestras por el grado de libertad de $z(n-3)$, con lo que se entrega mayor peso a las muestras más grandes (Rosenthal, 1991).

La homogeneidad de los resultados para las distintas muestras se probó usando chi-cuadrado, calculado como:

$$
\begin{aligned}
\mathrm{Z}=\frac{\left.\sum[\mathrm{Nj}-3) \mathrm{Zj}\right]}{\sum(\mathrm{Nj}-3)} \text { resultado de la fórmula se en tabla } \mathrm{X}^{2}(\mathrm{~K}-1) \\
\\
\mathrm{Nj}=\text { tamaño de cada uno de los estudios. } \\
\mathrm{Zj}=\text { efecto de cada uno de los estudios. } \\
\mathrm{K}=\text { número de estudios ponderados }
\end{aligned}
$$


La comparación del conjunto de las muestras diferenciadas en variables moderadoras, se realizó comparando las medias del tamaño del efecto para dos o más subconjuntos de muestras (Rosenthal, 1991).

\section{Tabla 2}

Composición de la muestra de los estudios por paises

\begin{tabular}{|c|c|c|c|c|c|c|c|c|}
\hline \multirow[b]{2}{*}{ Estudio } & \multirow{2}{*}{$\begin{array}{c}\text { Composición } \\
\text { por paises }\end{array}$} & \multirow[b]{2}{*}{$N$} & \multicolumn{3}{|c|}{ Edad } & \multirow{2}{*}{$\begin{array}{l}\text { Composición } \\
\text { de la muestra }\end{array}$} & \multicolumn{2}{|c|}{ Sexo } \\
\hline & & & $M$ & $D E$ & Rango & & $\begin{array}{l}\text { Hom- } \\
\text { bres \% }\end{array}$ & $\begin{array}{l}\text { Muje- } \\
\text { res \% }\end{array}$ \\
\hline \multirow{7}{*}{$\begin{array}{l}\text { Mendo- } \\
\text { za et al., } \\
2005\end{array}$} & España & 115 & 21 & 2,30 & $19-32$ & \multirow[t]{7}{*}{ Estudiantes } & 17 & 83 \\
\hline & País Vasco & 171 & 21 & 2,47 & $19-39$ & & 15 & 84 \\
\hline & Argentina & 314 & 23 & 4,98 & $19-53$ & & 23 & 77 \\
\hline & México & 106 & 22 & 3,88 & $18-46$ & & 17 & 83 \\
\hline & Chile & 113 & 23 & 3,99 & $16-58$ & & 37 & 63 \\
\hline & Brasil & 223 & 23 & 6,01 & $18-45$ & & 24 & 76 \\
\hline & Portugal & 108 & 21 & 4.47 & $17-47$ & & 9 & 91 \\
\hline \multirow{2}{*}{$\begin{array}{l}\text { Techio, } \\
2007\end{array}$} & España & 291 & 24 & 8,39 & $17-58$ & \multirow[t]{2}{*}{ Estudiantes } & 33 & 67 \\
\hline & Brasil & 324 & 22 & 5,06 & $17-58$ & & 17 & 83 \\
\hline \multirow{6}{*}{$\begin{array}{l}\text { Zlobina, } \\
\text { Basabe } \\
\text { \& Páez, } \\
2004\end{array}$} & Rusia & 71 & 38 & 11,64 & $22-76$ & \multirow{6}{*}{$\begin{array}{l}\text { Inmigrantes } \\
\text { en España }\end{array}$} & 42 & 58 \\
\hline & Brasil & 98 & 34 & 10,55 & $16-54$ & & 38 & 62 \\
\hline & Colombia & 290 & 34 & 9,88 & $16-60$ & & 43 & 57 \\
\hline & Ecuador & 311 & 30 & 7,17 & $18-56$ & & 44 & 56 \\
\hline & P. Árabes & 221 & 32 & 8,31 & $18-63$ & & 75 & 25 \\
\hline & África & 77 & 32 & 8,28 & $18-55$ & & 68 & 32 \\
\hline \multirow[t]{2}{*}{$\begin{array}{l}\text { Páez et } \\
\text { al., } 2006\end{array}$} & España & 450 & 28 & 12,64 & $13-62$ & $\begin{array}{l}\text { Estudiantes } \\
50 \%, \\
\text { familiares y } \\
\text { amigos } 50 \%\end{array}$ & 34 & 66 \\
\hline & Brasil & 160 & 23 & 4,89 & $17-48$ & Estudiantes & 17 & 83 \\
\hline \multirow{3}{*}{$\begin{array}{l}\text { Páez et } \\
\text { al., } 2006\end{array}$} & España & 103 & 24 & 5,01 & $19-47$ & Estudiantes & 47 & 53 \\
\hline & Chile & 77 & 25 & 4,97 & $18-42$ & & 53 & 47 \\
\hline & México & 46 & 20 & 1,04 & $19-24$ & & & 100 \\
\hline Total & & 3.665 & & & & & & \\
\hline
\end{tabular}




\section{Resultados}

Los resultados descriptivos de los tipos motivacionales de Schwartz, los objetivos generales y las supradimensiones de los valores, en relación con los aspectos cognitivos y afectivos del bienestar subjetivo, se presentan en la Tabla 3. Los valores presentan correlaciones medias positivas en la mayoría de los casos, siendo los valores de auto trascendencia los de medias más altas para satisfacción con la vida y los de apertura al cambio para la felicidad. El valor de poder es el único con correlaciones medias negativas, es decir, que disminuirían el bienestar subjetivo de las personas. La relación entre los valores individuales de Schwartz y los aspectos cognitivos o de satisfacción con la vida y afectivos o de felicidad del bienestar quedó plenamente confirmada (ver Tablas 4 y 5 ).

\section{Valores de Schwartz y satisfacción con la vida}

Los resultados del análisis de las $r$ media con el método propuesto por Rosenthal (1991), presentan una correlación con ambas supradimensiones de colectivismo e individualismo, señalando que serían importantes para la satisfacción con la vida (ver Tabla 4). Analizando los valores individuales, se obtiene que las dimensiones que aportarían más fuertemente a la satisfacción con la vida son hedonismo, benevolencia y auto dirección, seguidas de universalismo y seguridad, más débilmente tradición y estimulación. El valor individual de poder muestra una fuerte relación en contra de la satisfacción con la vida. Conformismo y logro, mientras tanto, no presentan una relación significativa con la satisfacción con la vida.

Con relación a los objetivos generales descritos por Schwartz, la auto trascendencia marca significativamente la satisfacción con la vida, seguida por la apertura al cambio y, en menor medida, el conservadurismo. Los resultados muestran también que estas relaciones son bastante robustas ya que, como se observa en la última columna de la Tabla 4, el número de estudios en contra para la mayoría de los casos es muy alto para desafiar la significación encontrada. 
Felicidad, cultura y valores personales / Bilbao, Techio y Páez

\section{Tabla 3}

Estadisticos descriptivos, basados en r media, de los valores de Schwartz con satisfacción con la vida y con felicidad

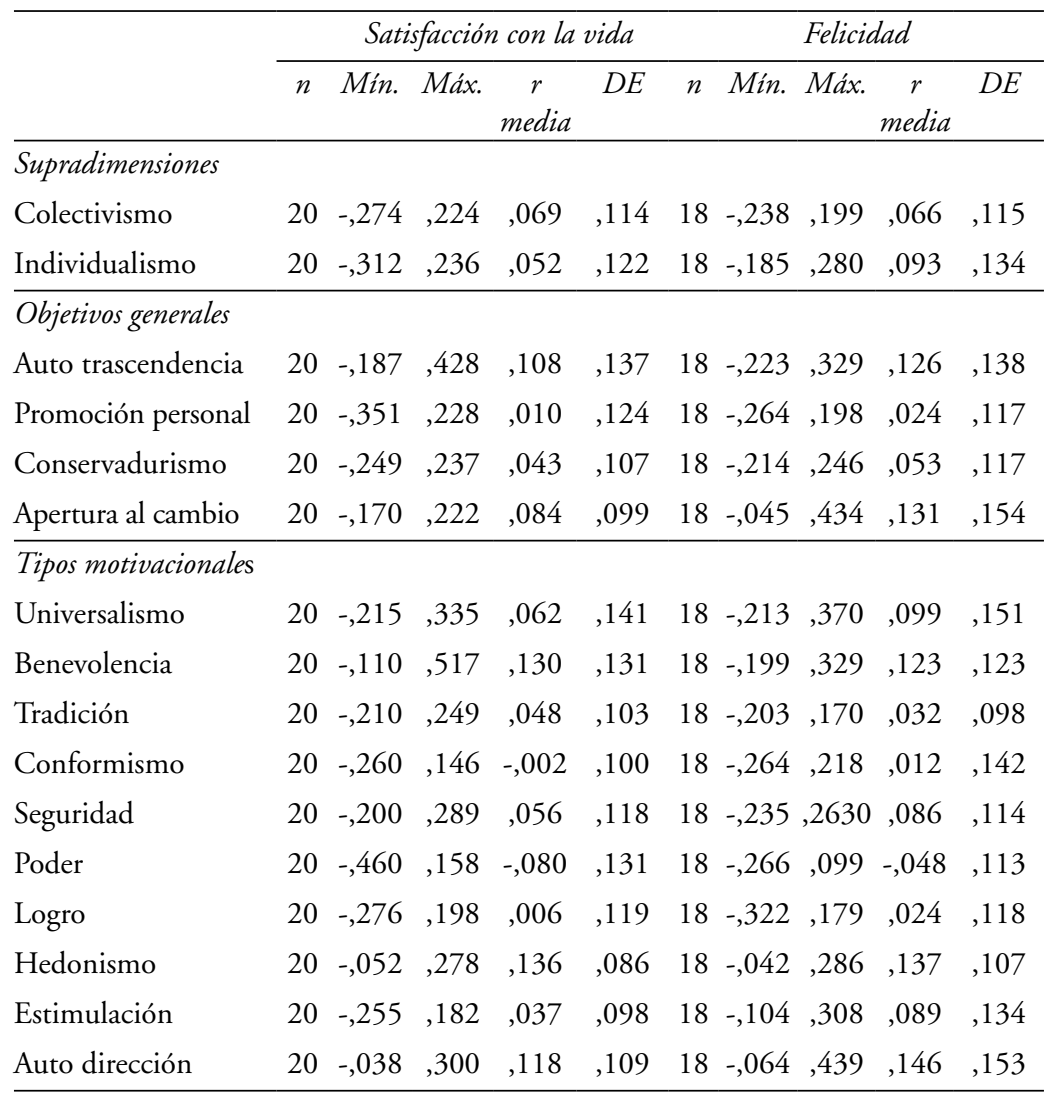




\section{Tabla 4}

Valores de $r$ media, homogeneidad en estudios y número de estudios necesarios para anular asociación de valores de Schwartz y satisfacción con la vida

\begin{tabular}{|c|c|c|c|}
\hline & $r$ media & Homogeneidad & $N^{o}$ estudios contra \\
\hline \multicolumn{4}{|l|}{ Supradimensiones } \\
\hline Colectivismo & $.081^{* * *}$ & Sí & 261 \\
\hline Individualismo & $.061^{* *}$ & No & 139 \\
\hline \multicolumn{4}{|l|}{ Objetivos generales } \\
\hline Auto trascendencia & $.127^{* * *}$ & No & 672 \\
\hline Promoción personal & .011 & Sí & \\
\hline Conservadurismo & $.051^{*}$ & Sí & 92 \\
\hline Apertura al cambio & $.099^{* * *}$ & No & 400 \\
\hline \multicolumn{4}{|l|}{ Tipos motivacionales } \\
\hline Universalismo & $.073^{* *}$ & No & 208 \\
\hline Benevolencia & $.149^{* * *}$ & No & 1038 \\
\hline Tradición & $.052^{*}$ & Sí & 110 \\
\hline Conformismo & .001 & Sí & \\
\hline Seguridad & $.071^{* *}$ & Sí & 220 \\
\hline Poder & $-.085^{* * *}$ & Sí & 330 \\
\hline Logro & .007 & Sí & \\
\hline Hedonismo & $.160^{* * *}$ & Sí & 1070 \\
\hline Estimulación & $.044^{*}$ & Sí & 61 \\
\hline Auto dirección & $.139^{* * *}$ & No & 800 \\
\hline
\end{tabular}

${ }^{*} p<.05 ;{ }^{* *} p<.01 ;{ }^{* * *} p<.001$

\section{Valores de Schwartz y felicidad}

Los resultados de los aspectos afectivos del bienestar asociados a los valores de Schwartz muestran resultados similares, pero aun más fuertes, lo que implicaría una influencia mayor de éstos en la apreciación global de felicidad de las personas. Las supradimensiones estarían aportando de manera significativa a la felicidad, siendo los valores de individualismo los más fuertemente correlacionados, seguidos de los valores de colectivismo (ver Tabla 5). Con relación a los objetivos generales descritos 
por Schwartz, la apertura al cambio y la auto trascendencia marcan significativamente la felicidad, aportando también, aunque en menor medida, el conservadurismo. El análisis de los valores individuales muestra que las dimensiones que aportarían más fuertemente a la felicidad son la auto dirección, el hedonismo, la seguridad y la benevolencia, seguidas de universalismo y estimulación, y más débilmente tradición. El valor personal de poder muestra una relación inversa significativa con felicidad, confirmando el efecto perjudicial para el bienestar subjetivo de estos valores, similar a lo observado anteriormente con relación a la satisfacción con la vida. El conformismo y el logro, mientras tanto, no presentan una relación significativa con la felicidad (ver Tabla 5).

\section{Tabla 5}

Valores de r media, homogeneidad en estudios y número de estudios necesarios para anular asociación de valores de Schwartz y felicidad

\begin{tabular}{lccc}
\hline & rmedia & Homogeneidad & $N^{o}$ estudios contra \\
\hline Supradimensiones & & & \\
Colectivismo & $.079^{* * *}$ & Sí & 187 \\
Individualismo & $.112^{* * *}$ & No & 395 \\
\hline Objetivos generales & & & \\
Auto trascendencia & $.151^{* * *}$ & No & 740 \\
Promoción personal & .029 & Sí & - \\
Conservadurismo & $.063^{* *}$ & Sí & 113 \\
Apertura al cambio & $.157^{* * *}$ & No & 801 \\
\hline Tipos motivacionales & & & 457 \\
Universalismo & $.120^{* * *}$ & No & 749 \\
Benevolencia & $.143^{* * *}$ & No & 45 \\
Tradición & $.041^{*}$ & Sí & - \\
Conformismo & .022 & No & 482 \\
Seguridad & $.155^{* * *}$ & Sí & 68 \\
Poder & $-.048^{*}$ & No & - \\
Logro & .028 & Sí & 878 \\
Hedonismo & $.164^{* * *}$ & No & 356 \\
Estimulación & $.106^{* * *}$ & No & 994 \\
Auto dirección & $.173^{* * *}$ & No &
\end{tabular}

${ }^{*} p<.05 ;{ }^{* *} p<.01 ;{ }^{* * *} p<.001$ 
Los resultados antes descritos muestran también relaciones bastante robustas, ya que el número de estudios en contra para la mayoría de los casos es muy alto para desafiar la significancia encontrada (ver Tabla 5).

\section{Diferencias culturales}

Se observaron diferencias al realizar un análisis detallado de la homogeneidad de los estudios, es decir, las muestras utilizadas no deberían considerarse como correlaciones características provenientes de una misma población. Al analizar las características de las muestras utilizadas, encontramos varias dimensiones sin homogeneidad entre los estudios, que podrían explicarse por las culturas de los participantes o su situación sociodemográfica (inmigrante versus estudiante).

En relación con los factores cognitivos y afectivos del bienestar subjetivo, el individualismo presenta mayor diferencia interna sin homogeneidad entre los estudios, marcado principalmente por las muestras de sujetos inmigrantes, quienes tienen niveles medios de relación entre bienestar e individualismo superiores a los de los estudiantes. Por otro lado, las muestras con estudiantes de México y Chile presentan correlaciones menores a las de otros países. España y Brasil muestran los niveles medios de la correlación entre bienestar e individualismo más altos con relación a todos los estudios.

La falta de homogeneidad encontrada en la dimensión de auto trascendencia está explicada por diferencias significativas entre las correlaciones de los estudiantes chilenos y los inmigrantes en España, teniendo los primeros una alta correlación entre los valores de trascendencia y el bienestar subjetivo $(F=4,008, p<.05)$. Por otro lado, los estudiantes españoles y brasileños muestran correlaciones medias superiores a las de otras muestras en apertura al cambio y bienestar, siendo las estudiantes mujeres mejicanas las de valores más bajos. 
Universalismo y benevolencia también presentan diferencias entre las muestras, las cuales estarían siendo explicadas por medias más bajas en las correlaciones de inmigrantes versus estudiantes $(t=2,973 ; p<.01)$.

\section{Discusión}

Los resultados del meta-análisis confirman una importante asociación entre los valores individuales y los distintos aspectos del bienestar subjetivo, señalando que en términos generales éstos favorecen la satisfacción con la vida y la felicidad de las personas. Cabe destacar que, si bien las asociaciones encontradas pueden parecer bajas, éstas se encontrarían en el primer tercio de magnitud — siguiendo los lineamientos empíricos de Hemphill (2003) — por lo que no deben ser desestimadas ya que, además, muestran una asociación significativa y relativamente estable para múltiples muestras y en distintos contextos culturales y sociodemográficos.

Los valores conservacionistas y colectivistas se asocian homogéneamente con el bienestar subjetivo. Estos resultados muestran una asociación significativa de nivel medio bajo entre conformismo, tradición y seguridad, una $r$ media de .08. Al igual que en el estudio de Lima y Novo (2006), los valores colectivistas se asocian a la satisfacción y la felicidad. Este resultado se puede traducir en que en personas con puntuaciones superiores a la media en valores colectivistas, el $54 \%$ estará por encima de la media en felicidad, frente al $46 \%$ de los que puntúen por debajo, según la estimación de Rosenthal (1991) que propone la presentación binomial del tamaño del efecto. Suponiendo que la variable dependiente se distribuye normalmente y se usa la media para distribuir a las personas en alta y baja felicidad, esta estimación es de $.50-\mathrm{r} / 2$ para los que puntúan bajo en la variable explicativa y de $.50+\mathrm{r} / 2$ para los que puntúan alto o $.50-.08 / 2=.46$ o $.50+.08 / 2=54$ respectivamente. 
Los valores de promoción personal o del yo muestran una asociación neutra homogénea con la satisfacción y la felicidad, lo que sugiere que son valores que no se asocian al bienestar subjetivo de forma central. Ahora bien, el poder se asocia ligera y negativamente con el bienestar, siendo particularmente significativa esta asociación con los aspectos más cognitivos del bienestar (satisfacción vital).

Los valores de auto trascendencia se asocian a la felicidad y satisfacción de forma positiva con una $r$ media de .13 , aunque de forma no homogénea. El hecho de que las asociaciones son más bajas en los inmigrantes que en los estudiantes de todos los países se puede interpretar como que estos valores, si bien refuerzan facetas del bienestar, lo hacen más claramente en contextos individualistas horizontales y post-materialistas, en los que estos valores son normativos. Esta interpretación se ve apoyada por los resultados obtenidos por Ramos (2006) con 10 países europeos. Ahora bien, comparaciones entre valoración de autóctonos españoles trabajadores jóvenes con inmigrantes en España, no mostraron diferencias ni que los inmigrantes puntuaran más bajo en auto trascendencia (Páez \& Zlobina, 2007). Podemos pensar que esto se explica por una diferencia entre clases, alternativamente.

Los valores de Apertura al Cambio (estimulación y auto dirección) se asocian fuertemente al bienestar, con una $r$ media de .16 a la felicidad. Se puede decir que de las personas que puntúan alto en estos valores, un 58\% puntúa alto en felicidad, frente al $42 \%$ de los que puntúan bajo. Los valores individualistas se asocian de forma similar aunque un poco más bajo a la felicidad, probablemente dado que estos valores unen el hedonismo a los de apertura al cambio y, como se verá más adelante, es el hedonismo el que se asocia más débilmente a criterios de salud mental, aunque no a satisfacción y felicidad. La $r$ media de apertura al cambio fue de .06 y sugiere que de las personas que puntúan alto en estos valores, un $53 \%$ puntúa alto en felicidad. 
Los valores de apertura al cambio muestran una asociación más fuerte en el caso de los inmigrantes que los autóctonos españoles, lo que se puede interpretar como un efecto de congruencia. Las comparaciones de acuerdo de los inmigrantes con los españoles en valores encontraron que estos eran más conservacionistas (estaban más de acuerdo con valores de tradición y seguridad) aunque puntuaban igual en apertura a la experiencia y algo menor en valores individualistas - sólo puntuaban más bajo en hedonismo. Esto sugiere un efecto de congruencia: los valores compartidos con los autóctonos y coherentes con la cultura individualista de Europa continental se asocian más fuertemente en personas que provienen de entornos más colectivistas al aculturarse en un entorno que lo es menos. Cabe destacar que los valores colectivistas no se asocian más débilmente entre los inmigrantes, lo que rechaza una explicación por incongruencia - compartir valores menos normativos sería un obstáculo al bienestar. Finalmente, los valores individualistas se asociaban menos fuertemente al bienestar en países americanos de contexto más colectivista como México y Chile — aunque no en Brasil que es un país medio en individualismo. Esto se puede interpretar como un efecto de incongruencia: valores adaptativos, como la auto dirección y la estimulación, se asocian más débilmente a la felicidad en contextos en los que estos son menos normativos.

\section{ESTUDIO DOS \\ VALORES DE SCHWARTZ Y CRITERIOS DE SALUD PSICOSOCIAL}

Con el fin de entender cuáles son los aspectos de la salud psicosocial que cada conjunto de valores refuerza, se analizó la relación entre los dominios de objetivos generales y valores de Schwartz con las facetas de bienestar psicológico, medidas por la Escala de Ryff (Díaz et al., 2006) y del bienestar social, utilizando la Escala de Keyes (Blanco \& Díaz, 2005). También se repitieron las correlaciones con felicidad medida por 
la Escala de Oxford (Argyle, 1987) y satisfacción con la vida medida por la Escala de Satisfacción con la Vida de Lucas, Diener y Suh (1996).

Las relaciones se estimaron en un país sudamericano de mayor colectivismo y jerarquía, con un menor índice de desarrollo humano como Brasil, y otro europeo, relativamente más individualista e igualitario, con un índice de desarrollo humano mayor como España (Basabe \& Ros, 2005).

\section{Metodología}

\section{Participantes}

El Estudio 2 utilizó muestras de Brasil y España (ver Tabla 6). Ambas muestras estuvieron constituidas principalmente por mujeres estudiantes universitarias de la carrera de psicología, aunque un tercio de la muestra de España incluyó también a padres y madres de los estudiantes.

\section{Tabla 6}

Composición de los estudios según pais, sexo y edad

\begin{tabular}{lccccc}
\hline País & $n$ & $\begin{array}{c}\text { Hombres } \\
\%\end{array}$ & $\begin{array}{c}\text { Mujeres } \\
\%\end{array}$ & $\begin{array}{c}\text { Edad } \\
M(D E)\end{array}$ & Rango \\
\hline España & 468 & 34 & 66 & $26(10,2)$ & $17-60$ \\
Brasil & 160 & 17 & 83 & $22,7(4,9)$ & $17-48$ \\
Total & 628 & & & & \\
\hline
\end{tabular}

\section{Instrumentos}

1. Escala de Bienestar Social de Keyes (versión de Blanco \& Díaz, 2005): expone criterios interpersonales de evaluación de un buen funcionamiento psicológico. Evalúa la percepción que las personas tienen sobre cinco aspectos del entorno social que facilitan su bienes- 
tar psicológico. Las dimensiones de bienestar social correlacionan con alto afecto positivo, satisfacción con la vida y bajo afecto negativo y depresión, y son las siguientes:

- Aceptación social: la persona tiene una actitud positiva hacia los otros en general (creo que los otros son buena gente). Se asocia a percibir que las relaciones con otros permiten auto aceptarse y obtener autoestima.

- Actualización social: creer que el mundo social se desarrolla o puede desarrollarse para mejor (yo creo que el mundo se está transformando en un lugar mejor para todos). Se asocia a percibir que el entorno permite el crecimiento personal.

- Contribución social: sentimiento de tener algo positivo que dar a la sociedad y que las actividades de la persona son valoradas ( yo tengo algo de valor que aportar al mundo), facilitando la motivación y el propósito en la vida.

- Coherencia social: creencia en que el mundo es predecible, inteligible y lógico, así como preocuparse e interesarse por la comunidad, facilitando el manejo y dominio del medio (encuentro fácil predecir lo que va a ocurrir en la sociedad a corto plazo).

- Integración social: sentirse parte de la comunidad, sentirse que se pertenece, se está apoyado y se comparten cosas con el colectivo (mi comunidad es una fuente de confort), facilitando la satisfacción de las necesidades de apego, afiliación y pertenencia.

2. Escala de Bienestar Psicológico de Ryff (Díaz et al., 2006): el bienestar subjetivo implica tanto un juicio positivo sobre la vida y vivencia de felicidad, como una serie de atributos psicológicos asociados al buen desarrollo y ajuste de la persona. Esta escala expone criterios privados de evaluación de un buen funcionamiento psicológico y 
mide dimensiones positivas del bienestar psicológico, que la autora estableció teóricamente sobre las necesidades satisfechas, motivos y atributos que caracterizan a una persona en plena salud mental, que habían planteado ya varios autores clásicos. El bienestar psicológico correlaciona con alto afecto positivo, satisfacción con la vida y bajo afecto negativo y depresión. Las dimensiones que mide son las siguientes:

- Autonomía: capacidad de ser independiente, de regularse por normas internas y resistir a la presión social (tengo confianza en mis opiniones inclusive si son contrarias al consenso general).

- Auto aceptación: actitud positiva hacia el yo (me siento satisfecho conmigo mismo), asociada a la autoestima y el conocimiento de sí.

- Propósito en la vida: asociado a la motivación para actuar y desarrollarse (tengo clara la dirección y el objetivo de mi vida).

- Control o dominio del entorno: asociado al locus de control interno y a la alta auto eficacia (creo que soy bueno manejando las responsabilidades cotidianas).

- Relaciones positivas con otros: creencia de que se tienen relaciones de confianza, cálidas, de empatía y de intimidad con otros (la gente puede describirme como una persona que comparte, dispuesta a compartir su tiempo con otras).

- Crecimiento personal: asociado a la idea de evolución y aprendizaje positivo de la persona (mi vida es un continuo proceso de cambio, aprendizaje y desarrollo).

Se realizaron correlaciones unilaterales con $r$ de Pearson para estudiar la influencia de los valores de Schwartz con criterios de salud psicosocial, en general y según país. 


\section{Resultados}

\section{Conservacionismo, colectivismo y bienestar}

El conjunto de valores conservacionistas o colectivistas se asocia positivamente a varias facetas de bienestar social (Escala de Keyes), en particular a la actualización social o creer que el mundo social puede desarrollarse para mejor, y al propósito en la vida del bienestar psicológico (Escala de Ryff). Estos valores también disminuirían el bienestar psicosocial ya que se asocian negativamente a la autonomía, la aceptación social y la coherencia social, lo que podría indicar un sentimiento de opresión del contexto cultural en el que se vive.

Los valores de tradición se asocian positivamente a las dos facetas anteriores, actualización social y propósito en la vida, aunque también negativamente a la coherencia social o percepción del mundo social como inteligible y predecible.

Los valores de seguridad también se asocian a la actualización social, la contribución social y al propósito o sentido de la vida. Valorar la tradición y la seguridad contribuye al bienestar reforzando a la cultura como fuente de sentido, así como a una visión de desarrollo positivo de la sociedad. Los valores de seguridad se asocian además a la contribución social o creer que se aporta a la sociedad y que ésta valora lo que uno aporta, así como a la auto aceptación. Sin embargo, las personas que valoran mucho la Seguridad perciben menor coherencia social y menor aceptación o tienen una actitud menos positiva hacia la sociedad, con una percepción más negativa de las relaciones sociales y menor autonomía personal.

El conformismo, en cambio, no refuerza ninguna faceta del bienestar. Además, el conformismo se asocia negativamente con tres de las cinco facetas del bienestar social (aceptación, contribución y coherencia social), así como negativamente con la autonomía y el crecimiento personal (bienestar psicológico). 
Estos resultados son coherentes con los del meta-análisis, en el cual se encontraron asociaciones positivas con el bienestar subjetivo de los valores de tradición (satisfacción con la vida $r=.05, p<.05$ ) y seguridad (felicidad $r=.16, p<.001$ ), mientras que el conformismo no se asoció significativamente.

\section{Apertura al cambio, individualismo y bienestar}

Las asociaciones positivas entre los valores de apertura al cambio se dan más fuertemente con los criterios de bienestar psicológico que con los de bienestar social. El crecimiento personal es el más asociado a este valor, seguido por propósito en la vida, auto-aceptación, dominio del entorno, relaciones positivas con otros y, finalmente, con autonomía. Este orden variará al analizarlo por países (ver sección siguiente). En la asociación con bienestar psicosocial encontramos una fuerte asociación con integración social, seguida de contribución social y finalmente con coherencia social, lo que estaría señalando que los valores de apertura al cambio no sólo serían valores individualistas sino también que aportarían a la percepción de un clima social positivo. Como afirman Sheldon y Bettencourt (2002), la autonomía no es lo opuesto sino que un polo complementario a relaciones sociales satisfactorias y a un medio social controlable y que permite el desarrollo.

Si bien la estimulación y búsqueda de nuevos estímulos se asocia al bienestar social más que el hedonismo, sugiriendo que ser abiertos a nuevos estímulos refuerza más la integración y satisfacción social que el mero valorar los placeres de la vida, en cambio, son los valores hedonistas los que se asocian a más criterios de bienestar psicológico.

Los valores de auto dirección muestran una fuerte asociación con los criterios de bienestar. Las correlaciones encontradas con bienestar psicológico en todas las dimensiones varían de .27 a .40 ( $p<.001)$, señalando que los valores que aportan a la libertad y autonomía personal fortalecen la salud mental y este sentimiento de bienestar psicológico se reflejaría en una visión positiva de su contribución e integración a su sociedad. 


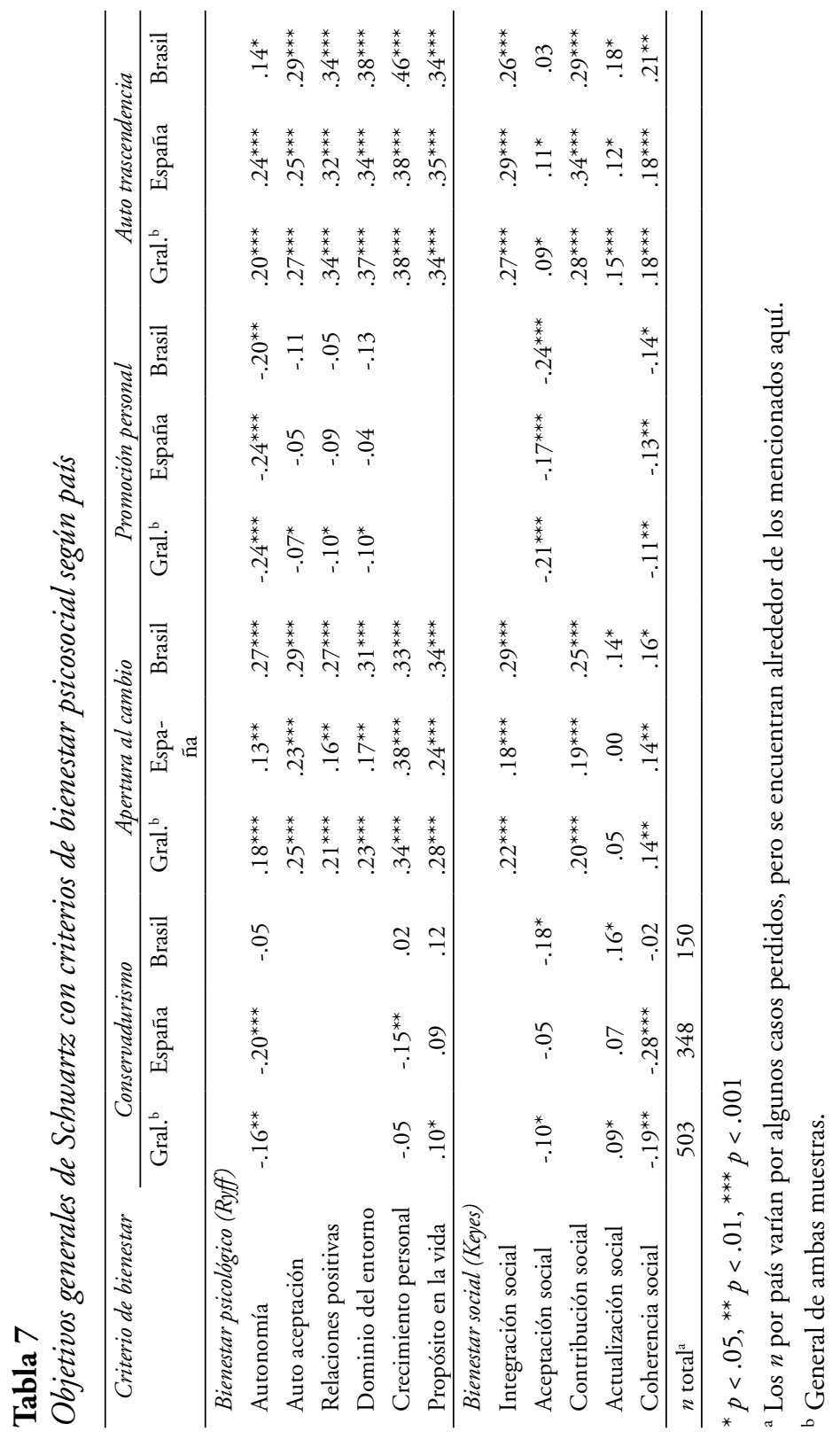




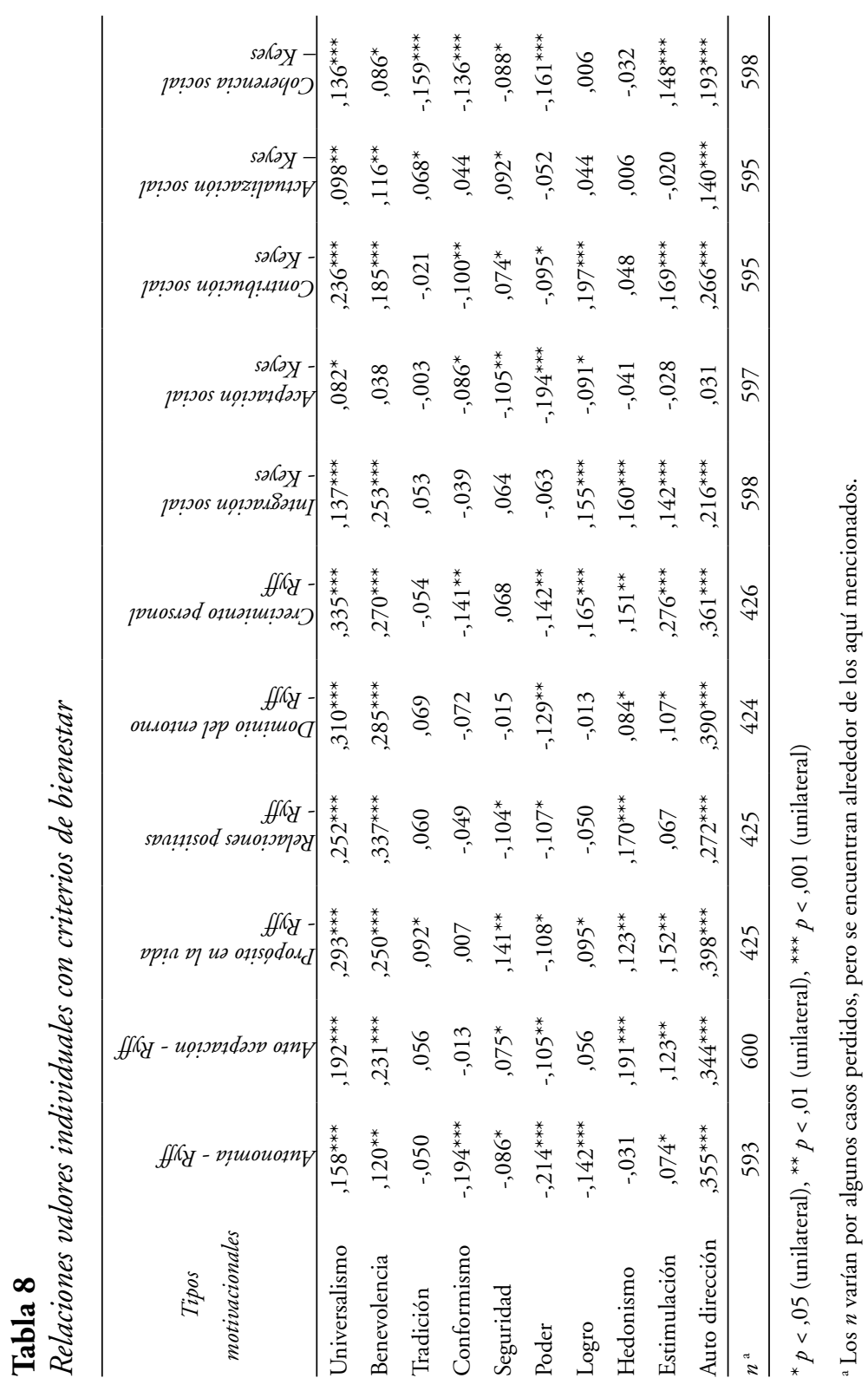


Estos resultados son bastante consistentes con los del meta-análisis, en el cual los valores de apertura al cambio marcaban fuertemente el aspecto afectivo del bienestar psicológico $(r=.16, p<.001)$, siendo auto dirección el valor personal con mayor aporte al bienestar subjetivo.

\section{Promoción personal y bienestar}

El conjunto de valores de promoción personal no se asocia positivamente a los criterios de bienestar. Es más, el valor de poder se relaciona significativamente de forma negativa con nueve de los 11 criterios de bienestar examinados y el de logro con seis de ellos (ver Tabla 8).

El objetivo general de promoción personal disminuiría la percepción de aceptación y coherencia social, además de generar una percepción de menor autonomía personal, menores relaciones positivas con otros y menor dominio del entorno. Las relaciones negativas se dan en particular con los valores de poder, que se asocia negativamente a tres criterios de bienestar social: actitud más negativa ante la sociedad, menor creencia que se aporta algo a esta y visión menos predecible de ella; así como a una relación negativa con todos los criterios de bienestar psicológico. Esto confirma los resultados del meta-análisis, que las personas que valoran el poder, la reputación y los bienes materiales -valores materialistas y de motivación extrínseca-, presentan menor felicidad, ya que se sentirían menos integrados socialmente y tendrían una visión más negativa de sus relaciones con otros.

Los valores de logro sí correlacionan positivamente con criterios de bienestar social y psicológico. Como muestra la Tabla 8, estos valores se asocian al propósito en la vida, al crecimiento personal o creer que uno se desarrolla en la vida y que esta tiene un sentido, así como a la integración social y a la contribución social o creer que se aporta algo de valor a la sociedad, confirmando que el valor de logro juega un papel positivo en la salud mental. Sin embargo, el logro también se asocia a una menor aceptación social o visión más crítica de la sociedad y a 
menor autonomía personal, mostrando que tiene aspectos que podrían perjudicar la salud mental personal.

Estos resultados son coherentes con los del meta-análisis, en el que los valores de logro tenían asociaciones positivas con el bienestar (aunque no significativas), mientras que el poder se asociaba negativamente de manera significativa $(r=-.09, p<.001)$.

\section{Auto trascendencia y bienestar}

Finalmente, los valores de auto trascendencia son los que tienen relaciones más fuertes con el bienestar social y psicológico. Esto es coherente con los resultados del meta-análisis, en el que la asociación más fuerte era con los valores de auto trascendencia que con los de apertura al cambio y estos más que con los de conservacionismo. Confirmando el carácter fuertemente social de la persona, los que valoran la justicia y el bienestar en general, además de preocuparse por el bienestar de las personas cercanas, son los que se sitúan más alto en todos los criterios. Aunque tanto el universalismo como la benevolencia muestran tamaños de asociación similares, los primeros valores refuerzan más la contribución social, el crecimiento personal y propósito en la vida, mientras que los valores de benevolencia se asocian más fuertemente a la integración social y relaciones positivas con otros y a la autoestima personal.

\section{Comparación entre países}

Los valores conservacionistas se asocian negativamente en España, y no en Brasil, con la autonomía $(r=-.20, p<.001)$ y con el crecimiento personal $(r=-.15, p<.01)$, así como con la coherencia social $(r=-.28$, $p<.001)$, mientras el conservacionismo se asocia más fuerte y positivamente a la actualización social en Brasil $(r=.16, p<.05)$ y negativamente con la actitud positiva ante los otros (aceptación social $r=-.18$, $p<.05)$. Es decir, los valores conservacionistas tendrían efectos negativos en un contexto individualista, pero más positivos en un contexto 
colectivista. Dado que el conservacionismo se asocia a una visión más negativa del mundo social en general, esta asociación se ve reforzada en un contexto colectivista.

Los valores de apertura al cambio muestran efectos más fuertes y positivos en Brasil que en España con todos los criterios de bienestar psicológico: autonomía, relaciones positivas con otros, dominio del entorno y propósito en la vida. Asimismo con los criterios de bienestar social de actualización, contribución e integración social (ver Tabla 7). Esto sugiere que en un contexto relativamente más colectivista, estos valores no tienen un efecto de rebote o contraste, sino que refuerzan el bienestar subjetivo, aunque la asociación con el crecimiento personal y con las otras dos facetas del bienestar social (coherencia y aceptación social) son similares en ambos países.

Los valores de promoción personal, se asocian negativamente de forma similar en ambos países, siendo significativa la influencia en autonomía, aceptación y coherencia social.

Finalmente, los valores de auto trascendencia se asocian más fuertemente con la autonomía y la aceptación y contribución social en España y con el crecimiento personal en Brasil. Estas diferencias se equilibran entre sí (por ser igualmente significativas casi todas las dimensiones en ambos países) y, dado que en el resto las asociaciones son similares, podemos concluir que los valores de universalismo y benevolencia son adaptativos en general y favorecen la salud mental de las personas.

\section{Conclusiones}

Nuestros resultados meta-analíticos, basados en muestras de estudiantes, autóctonos españoles e inmigrantes de América del Sur, Europa del Este y África, muestran una asociación homogénea y significativa de nivel medio bajo entre conformismo, tradición y seguridad $(r=.08)$. 
Esta conclusión, asociación media baja entre bienestar subjetivo y valores conservacionistas, sería coherente con el estudio de Lima y Novo (2006). Cabe destacar que, si bien a nivel societal el colectivismo se asocia a menor bienestar que el individualismo, confirmándose los hallazgos de investigaciones anteriores (Basabe \& Ros, 2005; Páez et al., 2004; Veenhoven, 1999), esto no se replica a nivel individual, en el cual estos valores favorecen principalmente la satisfacción con la vida. Esta asociación entre conservacionismo y bienestar se explicaría, según los resultados de nuestro segundo estudio, porque estos valores refuerzan los criterios de bienestar social que la sociedad se desarrolla para mejor y psicológico que la vida tiene propósito. Son los valores de tradición y seguridad sobre todo los que refuerzan la actualización social y atribuirle un sentido a la vida, aunque también las personas que valoran la tradición y seguridad perciben al mundo como menos predecible e inteligible. El valorar la conformidad no aporta al bienestar y más bien se asocia a una percepción más negativa, menos inteligible y que se aporta menos a la sociedad, así como a una imagen del yo más negativa -de menor auto aceptación, menor propósito y crecimiento vital.

Los efectos negativos de los valores conservacionistas en los criterios del bienestar psicológico y social fueron más fuertes en España y los positivos en Brasil, sugiriendo un efecto de congruencia: estos valores son menos adaptativos en contextos individualistas. Ahora bien, en el primer estudio se encontró que estos valores se asociaban de forma similar a la felicidad y satisfacción en todos los contextos, sugiriendo que la relación con la dimensión afectiva de estos valores es transculturalmente estable.

Los valores de promoción personal, asociados a culturas jerárquicas, de alta distancia al poder o autoritarias, aunque a nivel colectivo se asocian a menor bienestar, a nivel individual no se asocian a la felicidad. Podemos concluir que la asociación neutra se da porque se equilibran y anulan las asociaciones esencialmente negativas del poder con los criterios de salud mental con las asociaciones positivas del logro y hedo- 
nismo. Además, de forma similar se daban las asociaciones negativas con autonomía, aceptación social y coherencia social en ambos países, sugiriendo que los efectos negativos de los valores de poder sobre los criterios de bienestar psicológico y social son generales.

Podemos concluir con certeza que los valores de apertura al cambio y la experiencia — valores individualistas — , en particular la auto dirección, se asocian a la felicidad y el bienestar subjetivo de las personas. Ahora bien, los valores individualistas se asociaban menos fuertemente al bienestar en países americanos de contexto más colectivista como México y Chile, aunque no en Brasil que es un país medio en individualismo. Esto se puede interpretar como un efecto de incongruencia: valores adaptativos, como la auto dirección y la estimulación, se asocian más débilmente a la felicidad en contextos en los que estos son menos normativos. Esto es coherente con los análisis colectivos que muestran que el individualismo de una sociedad se asocia a mayor bienestar (Basabe \& Ros, 2005; Veenhoven, 1999). La relación positiva entre bienestar y apertura a la experiencia se explica porque estos valores se asocian con criterios de salud mental como la autonomía, el dominio o control, la auto eficacia y la autoestima, aunque también con el propósito en la vida y el crecimiento personal. Además, refuerzan las relaciones positivas con otros, una integración social en un medio que se percibe positivamente y que permite aportar a él. Se podría concluir que los valores de auto dirección y estimulación son más importantes para criterio de bienestar social y psicológico, mientras que los valores hedónicos se asocian más al componente de balanza de afectos y satisfacción de la felicidad.

El hedonismo se asocia sobre todo a criterios personales de salud mental, especialmente reforzando, mediante la exposición a situaciones y estímulos positivos, la autoestima y las relaciones positivas con otros, reforzando la afectividad positiva. La asociación más fuerte del hedonismo con la felicidad y satisfacción con la vida se explica porque por definición estos indicadores se asocian a una balanza de afectos o tonalidad afectiva positiva. 
La estimulación se asocia a variedad de experiencia, desafío y probablemente los criterios de salud mental de crecimiento personal y propósito en la vida, aunque también juega un papel importante reforzando la integración, coherencia y actualización social, probablemente mediante una orientación positiva hacia la diversidad y variedad de experiencia sociales. Aunque la estimulación era el valor que mostraba asociaciones más bajas con la satisfacción y felicidad. Los valores de apertura se asociaban más fuertemente al bienestar psicológico y social en Brasil que en España, sugiriendo que son adaptativos incluso en contextos donde éstos son menos normativos y que juegan un papel compensatorio en contextos colectivistas, aunque a nivel afectivo lo que había era una relación más débil en estudiantes viviendo en contextos colectivistas.

Los valores de auto trascendencia, junto con los de apertura al cambio, son los que tienen relaciones más fuertes con el bienestar subjetivo, tanto en su aspecto más afectivo — la felicidad - como en el cognitivo -la satisfacción con la vida. Esto es coherente con los resultados del meta-análisis, en el que la asociación era más fuerte con los valores de trascendencia que con los de apertura y con estos más que con los de conservacionismo. Los valores de universalismo y benevolencia se asociaban de forma similar al bienestar en Brasil y España, sugiriendo que son adaptativos en general. Por otro lado, la asociación de estos valores con la satisfacción y felicidad era más débil entre inmigrantes provenientes de América Latina, Europa del Este y África. Podemos concluir que estos valores, si bien refuerzan facetas del bienestar en general, lo hacen más claramente con la dimensión afectiva en contextos individualistas horizontales y post-materialistas, en los que estos valores son normativos.

En conclusión, podemos afirmar que valores conservacionistas, en particular aportando sentido a la vida, así como valores de apertura al cambio, reforzando la autonomía, y de auto trascendencia, reforzando las relaciones positivas con otros, son fines deseables que apoyan el bienestar subjetivo de las personas. Los valores se asocian más 
fuertemente al bienestar en general por un efecto principal o influencia positiva intrínseca, en algunos casos por congruencia (se asociaban menos fuertemente los valores individualistas al bienestar en contextos colectivistas y más los de auto trascendencia en contextos igualitarios y postmaterialistas) y en otras escasas ocasiones de forma compensatoria (la asociación entre valores de apertura e individualistas con criterios de bienestar era mayor en contextos colectivistas).

\section{Referencias}

Argyle, M. (1987). The psychology of happiness. Londres: Routledge. Argyle, M. \& Martin, M. (1991). The psychological causes of happiness. En F. Strack, M. Argyle \& N. Schwartz (Eds.), Subjective well-being. Oxford: Pergamon Press.

Barrientos, J. (2005). Calidad de vida. Bienestar subjetivo. Una mirada psicosocial. Santiago: Universidad Diego Portales.

Basabe, N., Páez, D., Valencia, J., González, J. L., Rimé, B. \& Diener, E. (2002). Cultural dimensions, socioeconomic development, climate and emotional hedonic level. Cognition and Emotion, 16(1), 103-125.

Basabe, N., Páez, D., Valencia, J., Rimé, B., Pennebaker, J., Diener, E. et al. (2000). Sociocultural factors predicting subjective experience of emotion: A collective level analysis. Psicothema, 12, 55-69.

Basabe, N. \& Ros, M. (2005). Cultural dimensions and social behavior correlates: Individualism-collectivism and power distance. International Review of Social Psychology, 18(1), 189-225.

Blanco, A. \& Díaz, D. (2005). El bienestar social: su concepto y mediación. Psicothema, 17(4), 582-589.

Díaz, D., Rodríguez-Carvajal, R., Blanco, A., Moreno-Jiménez, B., Gallardo, I., Valle, C. et al. (2006). Adaptación española de las Escalas de Bienestar Psicológico. Psicothema, 18(3), 572-577. 
Diener, E., Lucas, R. E. \& Oishi, S. (2005). Handbook of positive psychology. Oxford: Oxford University Press.

Green, E., Deschamps, J. C. \& Páez, D. (2005). Variation of individualism and collectivism within and between 20 countries. Journal of Cross-Cultural Psychology, 36(3), 321-339.

Hemphill, J. F. (2003). Interpreting the magnitudes of correlation coefficients. American Psychologist, 58(1), 78-80.

Hofstede, G. (2001). Culture's consequences. Londres: Sage.

Inglehart, R., Basañez, M., Diéz-Medrano, J., Halman, L. \& Luijkx, R. (2003). Human beliefs and values. México D. F.: Siglo XXI.

Kasser, T. \& Ahuvia, A. C. (2002). Materialistic values and well-being in business students. European Journal of Social Psychology, 32, 137-146.

Lima, M. L. \& Novo, R. (2006). Nós por cá todos bem? Bem-estar subjetivo e social em Portugal e na Europa. En J. Vala \& A. Torres (Eds.), Contextos e attitudes sociais na Europa. Lisboa: Instituto de Ciências Sociais.

Lucas, R. E., Diener, E. \& Suh, E. (1996). Discriminant validity of well-being measures. Journal of Personality and Social Psychology, 71, 616-628.

Mendoza, R., Páez, D., Marques, J., Techio, E. \& Espinosa, A. (2005). Control social subjetivo y valores culturales: estudio transcultural experimental sobre el efecto oveja negra y un estudio de campo sobre el 11-M. Revista de Psicología Social, 20(3), 289-300.

Páez, D., Campos, M., Jiménez, A. \& Techio, E. M. (2006). Cuaderno de prácticas de psicología social y salud. San Sebastián: Ibaeta Psicología.

Páez, D., Fernández, I., Ubillos, S. \& Zubieta, E. (2004). Psicología social, cultura y educación. Madrid: Pearson Prentice.

Páez, D. \& Zlobina, A. (2007). Los caminos de aculturación y el papel de la cultura para la interacción intercultural y la adaptación de los inmigrantes. En J. Igartua \& C. Muñiz (Eds.), Medios de comunicación, inmigración y sociedad. Salamanca: Universidad de Salamanca. 
Páez, D. \& Zubieta, E. (2004). Dimensiones culturales individualismocolectivismo como síndrome cultural. En D. Páez, I. Fernández, S. Ubillos \& E. Zubieta (Eds.), Psicología social, cultura y educación. Madrid: Pearson Prentice.

Ramos, A. (2006). Dinâmicas dos valores sociais e desenvolvimento socioeconómico. En J. Vala \& A. Torres (Eds.), Contextos e attitudes sociais na Europa. Lisboa: Instituto de Ciências Sociais.

Rosenthal, R. (1991). Meta-analysis procedures for social research. Newbury Park, CA: Sage.

Sagiv, L. \& Schwartz, S. H. (2000). Values priorities and subjective wellbeing: Direct relations and congruity effects. European Journal of Social Psychology, 30, 177-198.

Schwartz, S. H. (1992). Universals in the content and structure of values: Theoretical advances and empirical tests in 20 countries. En M. Zanna (Ed.), Advances in experimental social psychology (Vol. 25). San Diego: Academic Press.

Sheldon, K. M. \& Bettencourt, B. A. (2002). Psychological need-satisfaction and subjective well-beings within social groups. British Journal of Social Psychology, 41, 25-38.

Sidanius, J. \& Pratto, F. (1999). Social dominance. Cambridge, MA: Cambridge University Press.

Suh, E. M. (2000). Self, the hyphen between culture and subjective well-being. En E. Diener \& E. M. Suh (Eds.), Culture and subjective well-being (pp. 63-86). Massachusetts: MIT.

Techio, E. M. (2007). Relaciones intergrupales: factores socio-estructurales como predictores del estereotipo, discriminación y prejuicio ante grupos regionales. Tesis de doctorado no publicada, Universidad del País Vasco, España.

Vala, J. \& Torres, A. (Eds.). (2006). Contextos e attitudes sociais na Europa. Lisboa: Instituto de Ciências Sociais.

Vansteenkiste, M., Duriez, B., Simons, J. \& Soenens, B. (2006). Materialistic values and well-being among business students: Further evidence of their detrimental effect. Journal of Applied Social Psychology, 36(12), 2892-2908. 
Veenhoven, R. (1994). El estudio de la satisfacción con la vida. Intervención Psicosocial, 3, 87-116.

Veenhoven, R. (1999). Quality-of-life in individualistic society: A comparison in 43 nations in the early 1990's. Social Indicators Research, 48, 157-186.

Warr, P., Barter, J. \& Brownbridge, G. (1983). On the independence of positive and negative affect. Journal of Personality and Social Psychology, 44, 644-651.

Zlobina, A., Basabe, N. \& Páez, D. (2004). Adaptación de los inmigrantes extranjeros en España: superando el choque cultural. $M i$ graciones, 5, 43-84.

Recibido 10 de mayo, 2007 Aceptado 18 de junio, 2007 